\title{
RECTUS SHEATH BLOCK IN RECESSIVE DYSTROPHIC EPIDERMOLYSIS BULLOSA INVERSA FOR OVARIAN CYSTECTOMY; A CASE REPORT
}

Sandra Fernandez-Caballero, Maria Perez-Herrero.

Department of Anesthesiology, Hospital Clinico Universitario de Valladolid, Spain.

\section{BACKGROUND AND AIMS}

Recessive dystrophic epidermolysis bullosa inversa (RDEB-I) is a rare variant of dystrophic epidermolysis bullosa, characterized by bulla formation and erosions in body flexures and oral and esophageal mucosa.

We describe an anesthetic management with ultrasound-guided rectus sheath block in a patient with RDEB-I for ovarian cystectomy.

\section{METHODS}

A 29-year-old woman, diagnosed with RDEB-I at birth and esophageal stenosis that required endoscopic dilation, was scheduled for laparoscopic ovarian cystectomy. In the operating room the patient was monitored carefully, due the possibility of the development of new bullae. The facial mask was lubricated with Vaseline and was applied gently to avoid any trauma. For the induction of anesthesia, midazolam, propofol $2 \mathrm{mg} / \mathrm{kg}$ and rocuronium $0.6 \mathrm{mg} / \mathrm{kg}$ were used. She was successfully intubated, after video laryngoscopy, with a normal sized tube. A bilateral rectus sheath block was performed using the ultrasound probe (Fig.1), a 18G, 50-cm needle was inserted and $10 \mathrm{ml}$ of $0.25 \%$ bupivacaine was injected in each side (Fig.2). During the procedure, $2 \%$ sevoflurane was administered. The patient was extubated and taken to the recovery room without complications.

\section{RESULTS}

We noticed no complications nor any postoperative pain with regional anesthesia.

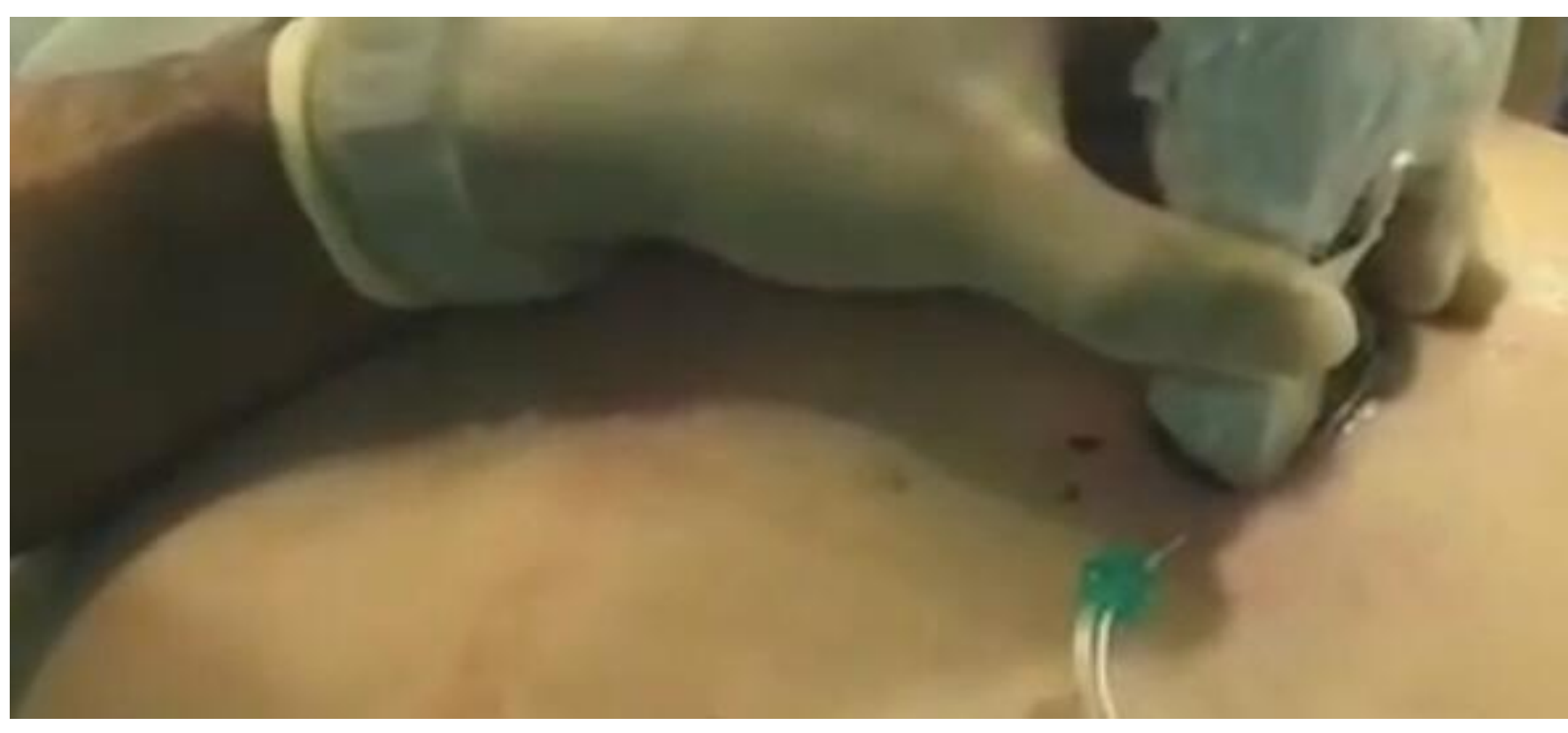

(Fig.1) Ultrasound probe

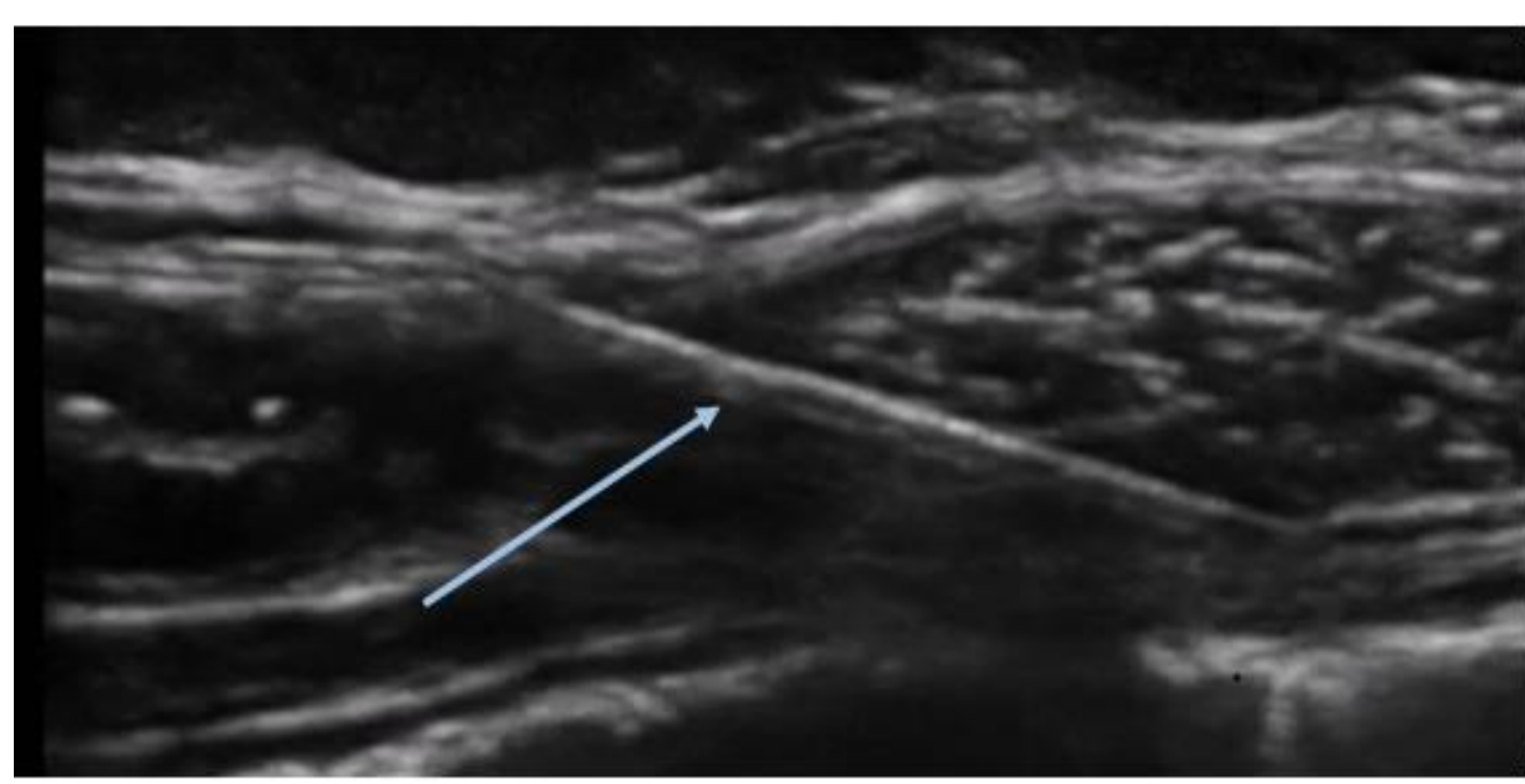

(Fig.2) Bupivacaine was inyected

No perioperative opioids were used to avoid any possible itching.

\section{CONCLUSION}

Regional anesthesia is a useful option for patients with RDEB-I. Rectus sheath block guided by ultrasound, provides excellent opioid-free analgesia as well as the reduction of complications in those kinds of patients. No bullae on the airway. 